\title{
ELECTRONICS AND RADIO ENGINEERING
}

\section{A УРT-1M Accelerator for Radiation Technologies}

\author{
S. Yu. Sokovnin ${ }^{a}$, M. E. Balezin ${ }^{b}$, and S. V. Shcherbinin ${ }^{b}$ \\ ${ }^{a}$ Ural Federal University, ul. Mira 19, Yekaterinburg, 620002 Russia \\ ${ }^{b}$ Institute of Electrophysics, Ural Branch, Russian Academy of Sciences, \\ ul. Amundsena 106, Yekaterinburg, 620016 Russia
}

Received December 27, 2011; in final form, July 26, 2012

\begin{abstract}
A УPT-1M modernized electron accelerator with an accelerating voltage up to $1 \mathrm{MV}$, a 1-kW electron beam power, and a 100-ns pulse duration is described. As compared to the prototype (YPT-1 accelerator), the layout of assemblies is changed in it, allowing one to place it in rooms with heights up to $2.5 \mathrm{~m}$. It uses Murata capacitors and a ТПИ1-10k/75 thyratron with a cold cathode for switching. The computer-aided parameter-monitoring system is created. A metal-ceramic cathode consisting of several elements with $\sim 15 \%$ nonuniform current density distribution of the electron beam on the exit foil was used to obtain an electron beam with a width of up to $400 \mathrm{~mm}$. The accelerator can be used in radiation technologies in layers with a thickness of up to $0.3 \mathrm{~g} / \mathrm{cm}^{2}$.
\end{abstract}

DOI: $10.1134 / \mathrm{S} 0020441213040106$

\section{INTRODUCTION}

The electron accelerators applied in radiation technologies should meet some requirements, in particular, such as economy, stability of parameters and reliability, and operation and repair simplicity. The УPT electron accelerators [1], based on a thyratronpulse transformer-semiconductor opening switch scheme [2], largely correspond to these requirements [1]. These accelerators can be used for modifying film polymers [3], radiation sterilization [4], and obtaining nanopowders [5], i.e., in radiation technologies on the surface, in gases and layers of liquid, loose or hard materials with a layer thickness of up to $0.3 \mathrm{~g} / \mathrm{cm}^{2}$.

During the operation of the УPT-1 electron accelerator [1], some drawbacks and imperfections were revealed, thus resulting in the necessity of its modernization. First of all, this relates to the accelerator design, which required a room equipped with a loadlifter with a $\sim 4-\mathrm{m}$ height to a hanger for its assembling-disassembling.
In addition, in many cases, it is required to irradiate objects with areas larger than the cross section of a $170-\mathrm{mm}$-diameter beam generated by the accelerator. The field experience of the УРT-0.5 accelerator at the NIIKhIT-2 [2], where it has been used for manufacturing separation materials for chemical current sources, showed a need for application in a vacuum diode of a $10^{-2}-\mathrm{Pa}$ pressure and higher during the long-term uninterrupted operation; otherwise, the cathodes quickly degrade.

It is necessary to note that the high cost and low reliability of КВИ-3-12 кВ-6800 нФ capacitors and a complex design of sections, consisting of such five series capacitors using a charging voltage of $\sim 50 \mathrm{kV}$ in the first circuit demonstrated expediency of using DHS capacitors (Murata Co., Japan) [6].

Note that a noticeable progress has been lately reached in creating cold-cathode thyratrons, allowing one to substantially increase the voltage switched by them to $100 \mathrm{kV}[7]$.

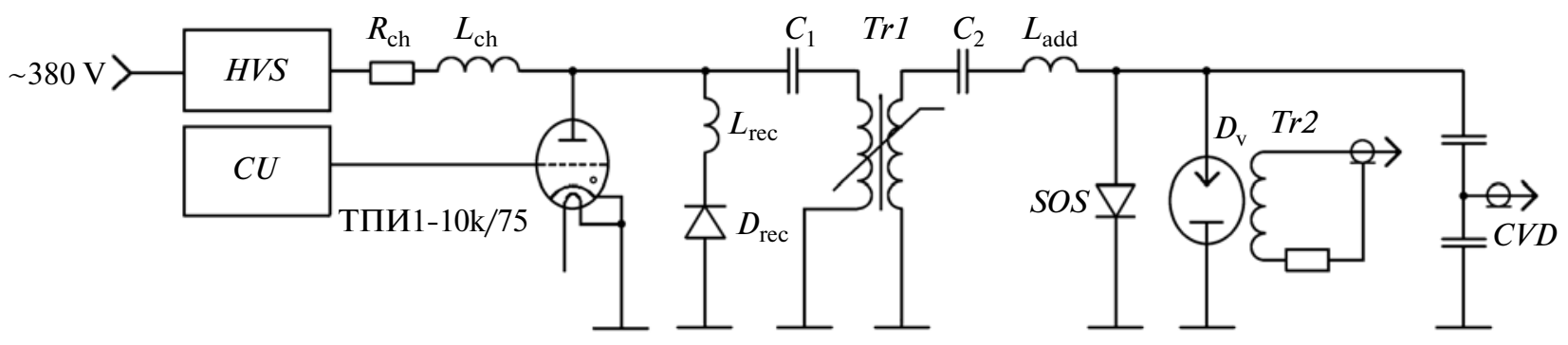

Fig. 1. УPT-1 accelerator scheme: $(H V S)$ high-voltage source; $(C U)$ control unit; $(S O S)$ semiconductor opening switch; $(C V D)$ capacitive voltage divider; (ТПИ1-10k/75) thyratron; $(\operatorname{Tr} 1)$ pulse transformer; $(\operatorname{Tr} 2)$ current transformer; $\left(D_{\text {rec }}\right)$ recuperation diode; $\left(D_{\mathrm{v}}\right)$ vacuum diode; $\left(L_{\mathrm{ch}}, L_{\mathrm{rec}}, L_{\mathrm{add}}\right)$ charge, recuperation, and additional chokes, respectively; and $\left(C_{1}, C_{2}\right)$ capacitors of the first and second circuits. 


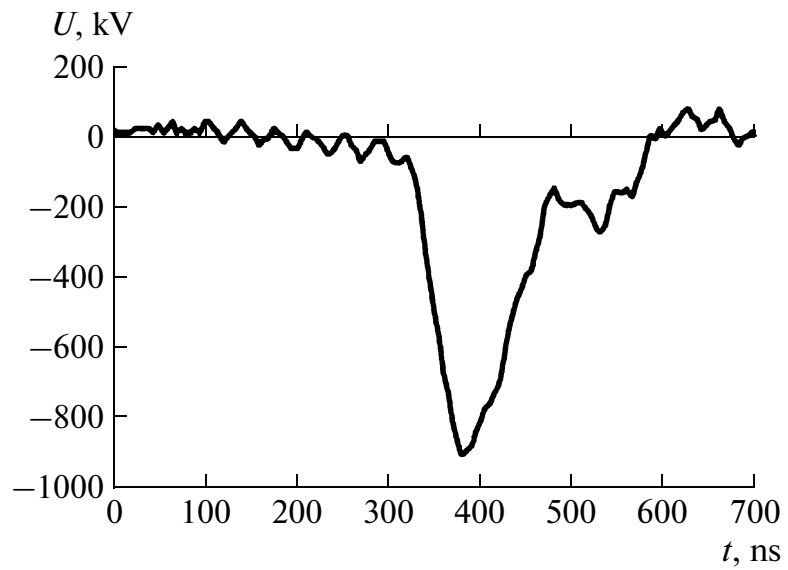

Fig. 2. Oscillogram of a voltage pulse.

At last, when accelerators uninterruptedly operate, it is required to automate monitoring of parameters.

\section{DESCRIPTION \\ OF THE ACCELERATOR DESIGN}

The accelerator scheme is shown in Fig. 1. Pulse transformer $\operatorname{Tr} 1$ is wound around the core consisting of two $50 \mathrm{H \Pi}$ permalloy K650 × $470 \times 25-\mathrm{mm} 20-\mu \mathrm{m}-$ thick rings between which there is a gap for cooling. The transformation ratio is 10 . The windings are made of a 0.5 -mm-thick copper strip: a $40-\mathrm{mm}$-wide strip was used for the primary winding, and a $15-\mathrm{mm}$-wide strip was used for the secondary winding. The primary winding overlaps approximately $1 / 3$ of the secondary one. Both windings are wound around a Plexiglas frame.

Plexiglas patches are additionally glued on the frame of the secondary winding to increase the electric strength. For more efficient magnetization reversal of the pulse-transformer core, the recuperation scheme is used; it consists of diode $D_{\text {rec }}$ (СДЛ 0.4/160) and inductance coil $L_{\text {rec }}(20 \mu \mathrm{H})$. The additional choke is selected experimentally $\left(L_{\text {add }}=8 \mu \mathrm{H}\right)$.

The capacitance value of the capacitor of the first circuit $C_{1}$ is $160 \mathrm{nF}$. It consists of 80 parallel sections; each contains two DHS4EG202KTZB series capacitors $(40 \mathrm{kV}, 2000 \mathrm{pF})$, allowing one to use a charging voltage of up to $70 \mathrm{kV}$ in this circuit. The capacitance value of the second circuit $C_{2}$ is $47.6 \mathrm{pF}$. It consists of
42 of the same series capacitors. А ТПИ1-10k/75 thyratron [7] is used for switching. The semiconductor opening switch (SOS) contains two parallel branches of four SOS-180-4 series diodes [2]. The high-voltage pulse formation unit is in transformer oil inside a metal housing.

The vacuum diode of the accelerator operates at a $\sim 10^{-3}$ Pa pressure, created by the НВД-250 vacuum diffusion pump, which is used instead of the АВД$150 / 25$ unit. This allowed one to slow down deterioration of the cathode emission, i.e., to increase their service life.

The vacuum insulator of the diode has a shielded dielectric surface [8]. The diode operates with a metal-dielectric cathode [9]. Exhaust windows that are $178 \mathrm{~mm}$ in diameter and $450 \times 100 \mathrm{~mm}$ in size are used to extract the beam. The windows have $85 \%$ transparency supporting aluminum grids consisting of slits and ribs with widths of 10 and $2 \mathrm{~mm}$, respectively. A $50-\mu \mathrm{m}$-thick aluminum foil is placed on the grids, and there is a closed channel for the water cooling along the perimeter of the grids.

A capacitive voltage divider $(C V D)$ was used to measure the voltage at the vacuum diode. The distribution of the absorbed dose of the electron beam in aluminum was measured using $\mathrm{CO}$ ПД(Ф) $\mathrm{P}-5 / 50$ dosimetry films [10]. The detectors were placed at a $5-\mathrm{cm}$ distance from the exit window of the vacuum diode behind different-thickness aluminum foil layers. The measurements were performed using 100 pulses applied with a $1-\mathrm{Hz}$ rate. The typical voltage pulse oscillogram is shown in Fig. 2.

The metal-ceramic (MC) cathode [11], consisting of several MC plates that were placed on one cathode holder (Fig. 3), was used to obtain a wide electron beam (up to $400 \mathrm{~mm}$ ). The plate sizes are $30 \times 18 \mathrm{~mm}$. The plates protrude beyond the gradient electrode edge by $10 \mathrm{~mm}$. The current distribution nonuniformity is $\sim 15 \%$ (Fig. 4). The current distribution can be controlled by changing the number and sizes of the MC plates (Fig. 5).

All high-voltage elements of the scheme are placed in a $1430 \times 980 \times 816$-mm carbon steel housing, whose mounting window occupies the full side wall, in contrast to the previous modification in which elements were mounted on the upper lid. This allowed us to improve the accelerator design and mount its elements

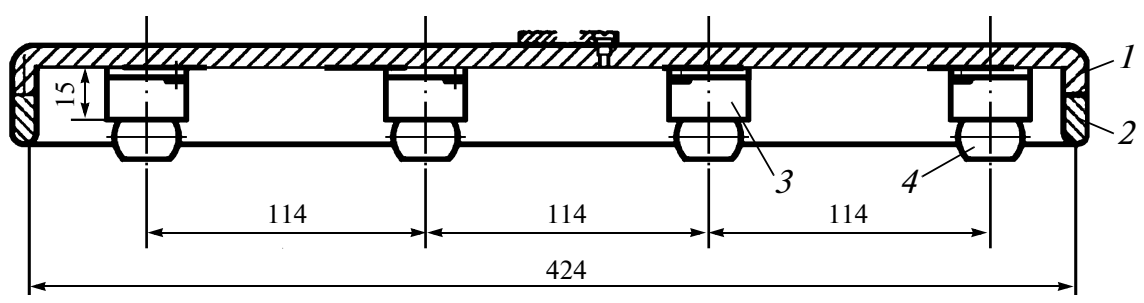

Fig. 3. MC cathode scheme with four plates: (1) cathode holder, (2) gradient electrode, (3) holder, and (4) MC plate. 


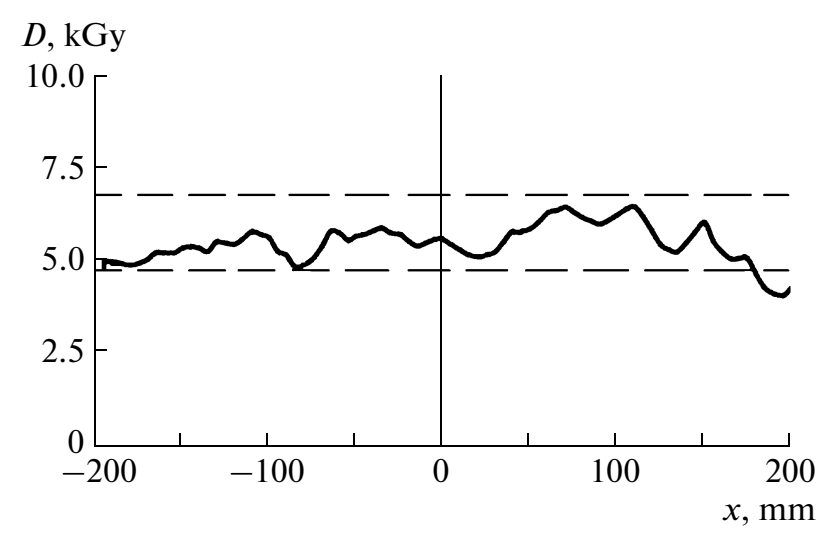

Fig. 4. Dose distribution for the 400-mm-long cathode. The dotted lines show the measurement error relative to the average value $( \pm 15 \%)$.

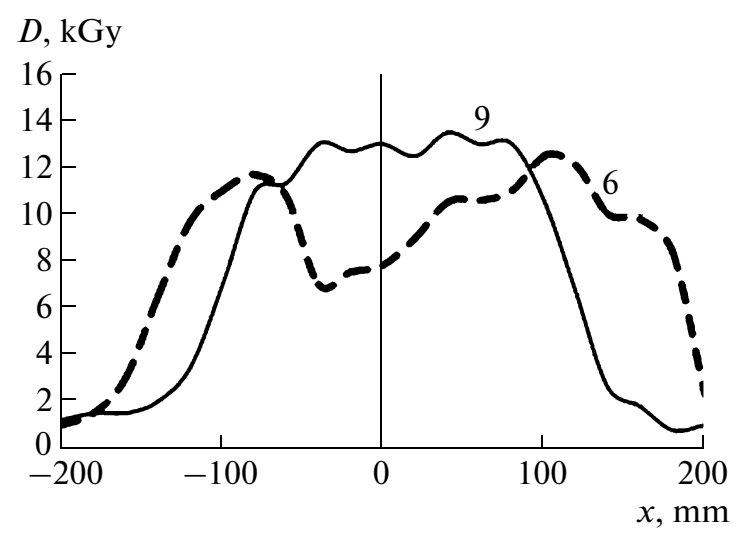

Fig. 5. Dependence of the dose distribution on the number of MC plates (figures near the curves). The cathode length is $200 \mathrm{~mm}$ and the MC plate sizes are $10 \times 10 \mathrm{~mm}$.

manually, without using load-lifting devices (crane), enabling placement of the accelerator in a $2.3-\mathrm{m}-$ height room.

\section{COMPUTER-AIDED PARAMETER- MONITORING SYSTEM OF THE ACCELERATOR}

The computer-aided control system (CCS) of parameters of the accelerator was modernized, as compared to the CCS of the УPT-0.5 accelerator, to constantly control operation of all systems of the accelerator and continuously monitor the voltage and current amplitudes of the output pulses [4].

The computer-aided control system contains a measurement unit and a control unit.

The measurement unit contains four channels for measuring voltage and current amplitudes of nanosec- ond pulses. Each channel is based on an amplitude detector and analog-to-digital converter (ADC). The information from all ADCs is collected and the received information is transmitted to the control unit by the ATMega8 microcontroller.

The control unit is based on the ATMega 162 microcontroller. In accordance with commands from the personal computer (PC), the unit sets the necessary pulse repetition rate and specifies the start and stop of accelerator triggering pulses. In addition, it processes signals from sensors that monitor the operation of the backup systems of the accelerator, such as the vacuum system, cooling system, and interlocks. Based on these signals, the control unit can stop feeding triggering pulses of the accelerator and produce a failure signal. All information arriving from the sensors and measuring unit is transmitted by the control unit to the PC to one of the COM ports through an optical isolator.

\section{ACKNOWLEDGMENTS}

We are thankful to research assistant V.G. Il'ves for his assistance in performing experiments.

\section{REFERENCES}

1. Sokovnin, S.Yu., Nanosekundnye uskoriteli elektronov $i$ radiatsionnye tekhnologii na ikh osnove (Nanosecond Electron Accelerators and Radiation Technologies on Their Basis), Yekaterinburg: Ural. Otd. Ross. Akad. Nauk, 2007.

2. Rukin, S.N., Instrum. Exper. Techn., 1999, vol. 42, p. 439.

3. Pletnev, V.P., Filimonova, L.G, Nazarova, T.M., and Sokovnin, S.Yu., Proc. 4th All-Russ. Bach Conf.. on Radiation Chemistry, Moscow: Izd. IFKhE RAN, 2005, p. 100.

4. Sokovnin, S.Yu., Balezin, M.E., Buldakov, I.A., Skotnikov, V.A., and Scherbinin, S.V., Izv. Vyssh. Uchebn. Zaved., Fiz., 2007, no. 10/2, p. 188.

5. Balezin, M.E., Bazarnyi, V.V., Karbovnichaya, E.A., and Sokovnin, S.Yu., Nanotechnol. Russ., 2011, vol. 6, p. 757.

6. http://www.murata.com/

7. Akimov, A.V., Logachev, P.V., Bochkov, V.D., et al., Proc. 16 th IEEE Int. Conf. Pulsed Power and Plasma Science, 2007, p. 1339.

8. Kotov, Yu.A., Filatov, A.L., Rodionov, N.E., et al., Prib. Tekh. Eksp., 1986, no. 2, p. 138.

9. Kotov, Yu.A., Sokovnin, S.Yu., and Balezin, M.E., Instrum. Esper. Tech., 2000, vol. 43, p. 102.

10. Abdulov, R.A., Generalova, V.V., Gurskii, M.N., Gromov, A.A., Zhanzhora, A.P., Pikaev, A.K., and Sysyk, A.E., High Energy Chem., 2002, vol. 36, p. 22.

11. Kotov, Yu.A., Sokovnin, S.Yu., and Balezin, M.E., RF Patent 2158982, Byull. Izobret., 2000, no. 31.

Translated by N. Pakhomova 